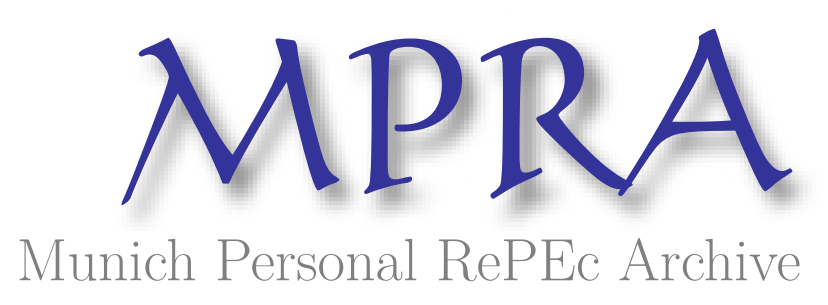

\title{
Market structure, counterparty risk, and systemic risk
}

Rosenthal, Dale W.R.

University of Illinois at Chicago

10 June 2009

Online at https://mpra.ub.uni-muenchen.de/36786/

MPRA Paper No. 36786, posted 20 Feb 2012 13:44 UTC 


\title{
MARKET STRUCTURE, COUNTERPARTY RISK, AND SYSTEMIC RISK
}

\author{
DALE W.R. ROSENTHAL
}

\begin{abstract}
Networks modeling bilaterally-cleared and centrally-cleared derivatives markets are shown to yield economically different price impact, volatility and contagion after an initial bankruptcy. A large bankruptcy in bilateral markets may leave a counterparty unable to expectationally prevent bankruptcy (checkmate) or make counterparties push markets and profit from contagion (hunting). In distress, bilateral markets amplify systemic risk and volatility versus centralized markets and are more subject to crises with real effects: contagion, unemployment, reduced tax revenue, higher transactions costs, lower risk sharing, and reduced allocative efficiency. Pricing distress volatility may suggest when to transition to central clearing. The model suggests three metrics for the well-connected part of a market - number of counterparties, average risk aversion, and standard deviation of total exposure - may characterize its fragility. (JEL: G01, G28, D49)
\end{abstract}

Systemic crisis is a recurring theme in finance. However, different markets have been seen to respond differently to distress. Therefore, it is important to study how these differences in distress might arise from differences in market structure. That is the goal of this paper.

Date: June 10, 2009 (first version); December 19, 2011 (this version). Department of Finance, University of Illinois at Chicago, 601 S. Morgan St (MC 168), Chicago, IL 60607, daler@uic.edu, tel. +1 312996 7170, fax +1 3124137948.

Thanks to Nitish Sinha, Florian Heider, Karlo Kauko, Chinmay Jain, Tim Johnson, Prachi Deuskar, Jeff Russell, Fangfang Wang, and Rob Engle; participants at the South Africa ISI, 2010 NYU/SoFiE systemic risk, Institut Louis Bachelier 4th long term risks, EFMA alternative investments, Geneva financial networks, Bank of Finland/SUERF/CEPR/JFI future of risk management, and 2011 FMA conferences; and, seminar participants at Northwestern, HKUST, and UIUC. I also thank colleagues from Long-Term Capital Management: The demise of the fund inspired and informed this research. Earlier versions were circulated as "The Effect of Market Structure on Counterparty Risk." 
Over the past fifteen years, crises at Askin Capital Management, Kidder Peabody, Long-Term Capital Management, Bear Stearns, American International Group, and Lehman Brothers have spread beyond those firms to affect markets and firms worldwide. Of particular interest is the epidemic nature of these crises: trouble at one firm spreads to other firms. Therefore, it makes sense to consider counterparty risk. In a strict sense, this is the direct risk to an institution due to a counterparty defaulting on a contract with that institution. In a broader sense however, we can consider how that default affects an institution indirectly (via other counterparties) or the overall market. Such indirect effects are often thought of as contagion and thus counterparty risk can lead to systemic risk.

Counterparty risk might seem to be a feature of over-the-counter (OTC) markets; however, many bonds are traded OTC without any worry of counterparty risk. Derivatives might seem to create counterparty risk since they are agreements between two parties; however, futures and options are derivatives and the CME and CBOE clearinghouses have never defaulted.

Two counterexamples to the above crises illustrate the difference. Refco was one of the largest US futures brokers when it went bankrupt due to fraud in 2005. MF Global was one of the largest futures broker-dealers in the US, Europe, and Australasia when it went bankrupt due to perceived risk of bets on Eurozone debt in 2011. Such bankruptcies would seem likely to cause anxiety among counterparties; however, the increase in volatility around these bankruptcies was small. Academics who study markets did not even notice Refco: there are no academic finance or economics papers discussing the failure. In contrast, the near-bankruptcy of Bear Stearns and bankruptcy of Lehman Brothers in 2007 caused chaos and interruptions in many OTC markets and are still being studied 
Why were Refco's and MF Global's bankruptcies comparatively placid? Part of the answer seems related to their having traded mostly futures: all the other crises mentioned involved OTC derivatives; and, in all of those cases the OTC markets largely ceased trading. In 1994, mortgage-backed securities largely ceased trading leading to the failure of a hedge fund (Askin) and the near-bankruptcy of an investment bank (Kidder Peabody). In 1998, the interest-rate swap spread and equity index volatility markets dried up as another large hedge fund (LTCM) failed. In 2007, the markets for credit default swaps and collateralized debt obligations ground to a halt as Bear Stearns nearly failed and Lehman went bankrupt. In all of these systemic crises, however, the CME, CBOE, and other futures and options exchanges continued to trade without interruption. ${ }^{1}$

One difference between these markets is in whether they use a central counterparty (CCP) or not. Many derivatives exchanges (including the CME and $\mathrm{CBOE}$ ) use a CCP; markets for swaps, swaptions, and the other instruments mentioned above do not use a CCP. Acharya, Engle, Figlewski, Lynch, and Subrahmanyam (2009) suggest that the lack of a CCP in these markets exacerbated the subprime financial crisis. That markets with CCPs continued trading while many markets without CCPs ceased trading suggests counterparty risk is a feature of market structure. Specifically: differences in network structure connecting counterparties may multiply or reduce the systemic effects of bankruptcy.

The importance of market structure with respect to systemic risk and contagion has been studied before, most notably by Allen and Gale (2000, 2004) and Nier, Yang, Yorulmazer, and Alentorn (2007). They primarily consider the interbank market and find that well-connected networks are

${ }^{1}$ For an example of the size of positions on one major futures exchange, Melamed (2009) gives the notional of CME contracts held at the time of these incidents as $\$ 761$ billion (Bear) and $\$ 1.15$ trillion (Lehman). 
more robust to shocks and less likely to exhibit contagion than sparse networks. Gai and Kapadia (2010) find that conditional on contagion, however, well-connected networks may be more fragile and yield greater destruction. As for markets with CCPs, Duffie and Zhu (forthcoming) find that more than one CCP may be inefficient and systemically riskier.

That market structure affects market volatility, default probabilities for counterparties, and the likelihood and perniciousness of contagion is of central importance to asset pricing because both volatility and default are priced risk factors. Increased volatility or volatility-induced losses may lead people and companies to reduce their holdings of risky instruments and, instead, horde cash. Increased volatility may widen bid-ask spreads, raising transactions costs at precisely the time when many people want to rebalance their portfolio. Increased volatility may also trigger the execution of limit or stop-loss orders. Further, the reducton of risky positions when they are likely to be undervalued may lock in losses. All of these situations also lead to allocative inefficiencies.

Systemic crisis is also important to corporate finance because volatility affects many decisions of the firm. Brunnermeier and Pedersen's (2009) model of the endogeneity of market and funding liquidity, verified by Boudt, Paulus, and Rosenthal (2011), suggests increased volatility may trigger lower market liquidity and thus a vicious cycle of decreasing market and funding liquidity. This means that counterparty risk may bleed over into the funding markets and affect non-financial businesses. This would affect firms' capital structures and, as a result, their taxation. Firms would also be more likely to horde cash instead of distributing it to shareholders or reinvesting in the firm. 
When counterparty risk induces an increase in follow-on bankruptcies, we get contagion and systemic risk. These bankruptcies simultaneously unemploy many people. ${ }^{2}$ This strains social welfare programs as those workers apply for benefits from the state while the unemployment shock reduces government revenue from payroll taxes and realized losses reduce corporate tax revenues. Bernanke (1983) has shown that such effects on financial firms may also lead to more expensive credit which affects non-financial firms and can lead to economic contraction or even depression. Thus counterparty risk and systemic crisis have economically significant real effects.

I use a two-period model to study the effects of a financial institution bankruptcy in an economy with one risky asset. The approach is general enough to be applied to any network structure and extended to multiple periods. Thus the approach could be used to design markets which most reduce the undesirable effects (externalities) studied here. The model is applied to two market-based network structures which represent markets with and without a central counterparty. Similar to Cifuentes, Ferrucci, and Shin (2005), Nier, Yang, Yorulmazer, and Alentorn (2007), and Gai and Kapadia (2010), I assume trading moves prices of the risky asset. However, the model excludes the effects of adverse selection on price discovery. This allows us to study differences in volatility and follow-on bankruptcies due strictly to market structure.

For these network structures, the model suggests that a central counterparty stabilizes the market by reducing post-bankruptcy volatility, undesired exposure through broken contracts, and contagion (follow-on bankruptcies). A central counterparty thus reduces systemic risk. This finding disagrees

\footnotetext{
${ }^{2}$ The effect of many people searching simultaneously for similar jobs can cause the labor market to undergo a concurrent crisis: troubled firms reduce hiring in the face of their own possible bankruptcy; and, stable firms wait to hire while the market price of that available labor deflates.
} 
with Allen and Gale (2000) and Nier, Yang, Yorulmazer, and Alentorn (2007) due to their models precluding separation of buying and selling rehedgers post-shock. ${ }^{3}$ Our model also allows us to predict the differences in systemic risk and distress responses between market structures for a given initial bankruptcy. This can even be extended to characterize a market's susceptibility to follow-on bankruptcies (i.e. contagion or market "criticality"). Thus this model implicitly suggests that reporting such data to a market monitor is beneficial.

\section{The Two-Period Network Model}

The economy we study has one risky underlying asset. Financial institutions (counterparties) trade OTC swaps on this asset. The only risk to the $n$ counterparties is that changes to the risky asset price affect the worth of their swap contracts. The risk-free rate is assumed to be 0 .

To simplify, we assume there is at most one contract between any two counterparties. (This is akin to netting contracts between counterparties.) The collection of counterparties and contracts defines a network: counterparties comprise the nodes of the network and contracts define its edges. Counterparties are endowed with capital and risk aversion. For simplicity, all counterparties start with the same capital $K$ and risk aversion $\lambda$. Contracts are endowed with signed sizes. These sizes may be constrained to give the network a certain topology. Counterparties begin in equilibrium, holding their desired exposure to the risky asset, and will seek to return to this exposure if perturbed from it. Contracts are continually marked-to-market: All gains and losses are realized after each trade in the market. Thus any cashflow which exceeds the remaining capital results in bankruptcy.

\footnotetext{
${ }^{3}$ The preclusion of separating buying and selling rehedgers is an artifact of their constructing well-connected networks from sparse networks, instead of vice versa as is done here.
} 
What the exposures mean is important. While we examine only one risky asset, a more complex world would have multiple risky assets. In that situation, we could view these exposures in two ways. If they are overall exposures to risk, counterparties might not seek to return to equilibrium. If they are positions in only one risky instrument, however, counterparties might hold counterbalancing positions; in that case, returning to equilibrium might be more natural. However, neither of these cases diminishes the seriousness of a capital-depleting cashflow. Even a firm with a counterbalancing position would surely see the dangers in matching the timing of such large cashflow movements.

Each trade affects the market by moving prices. This is modeled by a linear price impact model. For the duration of the modeled period, impact is permanent. That impact may or may not revert after the period modeled here. Neither of these would affect the results here. Thus one could view this impact as a pure service fee or as a charge for the possibility of adverse selection. A counterparty will therefore trade strategically given expected price impact, trading costs, and variance reduction. In the extreme, we can think of this as a no-seppuku rule: a counterparty will not rehedge completely if that rehedging would push it into bankruptcy

Trading occurs in a random sequence within a period. Price impact implies counterparties do not all rehedge at the same price. This leads to high and low prices "during" each period as well as an increase in market volatility. These price movements may cause some of the initially-living $n-1$ counterparties to go bankrupt.

All trading is done with a counterparty outside the network who has no concerns about risk or bankruptcy. One could appeal to an influx of liquidity providers in a crisis as justifying this approach. While it would be useful to 
have trades done with a market maker who learns and responds strategically, this would likely obscure which effects are due solely to market structure.

The model is a two-period model with trading in periods 1 and 2. At time $t=0$, bankruptcy of the $n$-th counterparty occurs; $n-1$ counterparties survive. Some or all of the living counterparties may have one of their contracts (connected edges) eliminated. At time $t=1$, each counterparty trades to maximize mean-variance utility given its desired exposure, the volatility of the risky asset, and expectations of others' actions. Follow-on bankruptcies may occur in period 1 . At time $t=2$, all remaining exposures due to the bankruptcy are hedged with trading again occurring in a random order. While follow-on bankruptcies may occur in period 2, these may result from the constraints inherent to a two-period model.

1.1. Notation. We introduce notation to express the dynamics of this model:

$$
\begin{aligned}
p_{t} & =\text { price of the risky asset at end of period } t \\
r_{t} & =\text { return of the risky asset in period } t \\
K & =\text { capital of each counterparty at start of period } 0 \\
\sigma & =\text { volatility per period of the risky asset price; and } \\
q_{i j} & =\text { exposure of counterparty } i \text { via contract with counterparty } j \neq i
\end{aligned}
$$

Worth noting is that the contract notation implies direction: $q_{i j}=-q_{j i}$.

The price impact model is linear in trade size so that it is as simple as possible and arbitrage-free as per Huberman and Stanzl (2004). If we assume price innovations are iid and have mean zero, we get the expected price for a trade by counterparty $i$ (absent other trading) as a function of the quantity rehedged $x_{i}$ :

$$
E\left(p\left(x_{i}\right)\right)=p_{0}+\underbrace{\pi x_{i}}_{\text {permanent }} .
$$


The price $p_{1}$ at the end of period 1 is:

$$
p_{1}=p_{0}+\sigma Z_{1}+\pi \sum_{j=1}^{n-1} x_{j}
$$

where $Z_{t \in\{1,2\}} \stackrel{i i d}{\sim}(0,1)$. While the end-of-period price is unaffected by the ordering of trades within the period, bankruptcies do depend on the path of prices in a period.

1.2. Network Topologies. While any network topology could be studied, we consider two market-based extremes. A star network with $n$ contracts represents a market with a central counterparty; a complete network with $n(n-1) / 2$ contracts represents a bilateral OTC market. Examples for four counterparties are shown in Figure 1.
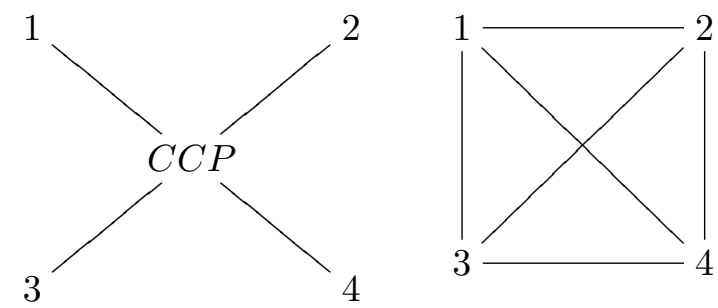

FiguRE 1. The two network structures considered shown for $n=4$ counterparties: a star network connected via a central counterparty (left) and a complete network (right).

The bankruptcy at $t=0$ affects these two topologies in different ways. For the star (centrally-cleared) network, the initial bankruptcy only invalidates one contract with the central counterparty $(\mathrm{CCP})$. For a complete (bilateral OTC) network, the initial bankruptcy invalidates contracts with $n-1$ living counterparties. 


\section{Two-Period AnAlysis}

With a few assumptions we can analyze the effect of the initial bankruptcy for these two network types. Contract sizes are assumed to have a zero mean

and finite variance: $q_{i j} \stackrel{i i d}{\sim}\left(0, \eta^{2}\right)$ for $i<j$ in the complete network. The star network has contract sizes equal to net exposures in the complete network. Counterparty $i$ has net exposure of $Q_{i}=\sum_{j} q_{i j}=q_{i, C C P}$. Net exposures have expectation 0 and variance $(n-1) \eta^{2}$.

After the initial bankruptcy $(t=1)$, living counterparties in a star network have no unwanted exposure; only the central counterparty has unwanted exposure to the risky asset. For a complete network, each living counterparty $i$ has unwanted exposure of $-q_{i n}$ reflecting the subtraction of the invalidated contract with the bankrupted counterparty.

Since the informational implications are different, we examine two cases: small and large initial bankruptcies.

2.1. Small Bankruptcy. We first consider the bankruptcy of a small financial firm. The small size suggests other counterparties have less information about the bankrupted firm. Thus bankruptcy may be due to market risk or idiosyncratic (management-related) factors. This is manifested in the capital at the start of period 1 being $K$ for each living firm. The only information living counterparties have about counterparty $n$ 's market exposure is their individual contracts with the bankrupted.

2.1.1. Star Network. In a star network, none of the living counterparties has a broken contract. Therefore none of the living are directly affected by counterparty risk nor need they rehedge. Since the living counterparties' contracts incur no default, there is no early signal that any counterparty has gone bankrupt. 
The central counterparty (CCP) takes on the bankrupted's exposure at time $t=1$. If the $\mathrm{CCP}$ rehedges immediately, the permanent price impact will be for a $-Q_{n}$-sized trade: $\Delta p=-\pi Q_{n}$.

The CCP has advantages over other counterparties: It knows all counterparties' positions and trades; and, it would have immediate evidence of predatory trading by a living counterparty. This lets the CCP rehedge to reduce price impact and avoid causing further bankruptcies.

Also relevant (but not in the model) are the CCP's operating and contractual agreements. The CCP might have a contractual claim against counterparties if it goes bankrupt. ${ }^{4}$ The CCP can also dictate margin and markto-market requirements to penalize large or risky positions. With these agreements, living counterparties have even stronger incentives not to move the market against the CCP. Thus while these details are outside the model, they further justify the CCP's trading to reduce price impact and contagion. ${ }^{5}$

Thus the CCP trades to maximize mean-variance utility:

$$
U_{C C P}(x)=\underbrace{-\pi x^{2}}_{\begin{array}{c}
\text { period 1 } \\
\text { impact }
\end{array}}-\underbrace{\lambda \frac{\sigma^{2}}{2}\left[Q_{n}^{2}+\left(Q_{n}+x\right)^{2}\right]}_{\text {variance penalty }}-\underbrace{\pi Q_{n}\left(Q_{n}+x\right)}_{\text {period } 2 \text { impact }}
$$

This yields an optimal period 1 trade size of:

$$
x_{C C P}=\frac{-\left(\pi+\lambda \sigma^{2}\right) Q_{n}}{2 \pi+\lambda \sigma^{2}} .
$$

Note that without price impact, the optimal policy is to rehedge completely in period $1\left(x_{C C P}=-Q_{n}\right)$. As linear price impact $\pi$ increases, the optimal trade tends toward an equal split of rehedging between periods 1 and 2. As volatility $(\sigma)$ increases, the optimal trade tends to rehedge completely in period 1 .

\footnotetext{
${ }^{4}$ The CME clearinghouse uses such a structure.

${ }^{5}$ Further research should examine when these incentives break down and members act against a CCP.
} 
2.1.2. Complete Network. In a complete network, bankruptcy by counterparty $n$ invalidates $n-1$ contracts. Each counterparty trades to rehedge their eliminated contract by the end of period 2. Since the bankruptcy is small, we ignore high and low prices triggering bankruptcies.

Each living counterparty chooses $x_{i}$ to maximize Markowitz mean-variance utility. This is the same as minimizing price impact (affecting exposure and the traded amount) plus the penalized variance of the unhedged exposure $\left(x-q_{i n}\right):$

$$
U_{i}(x)=\underbrace{-\pi x^{2}}_{\begin{array}{c}
\text { period } 1 \\
\text { impact }
\end{array}}-\underbrace{\lambda \frac{\sigma^{2}}{2}\left[q_{\text {in }}^{2}+\left(x-q_{i n}\right)^{2}\right]}_{\text {variance penalty }}-\underbrace{\pi q_{i n}\left(q_{i n}-x\right)}_{\text {period } 2 \text { impact }}
$$

When each counterparty knows nothing about the other counterparties' exposures, the optimal period 1 trade size is

$$
x_{i}=\frac{\left(\pi+\lambda \sigma^{2}\right) q_{i n}}{2 \pi+\lambda \sigma^{2}} .
$$

The sequencing of trades in periods 1 and 2 increases price volatility of the risky asset. The price volatility in periods 1 and 2 comes from equation (1) and the variation in contract sizes:

$$
\begin{aligned}
& \operatorname{Var}\left(p_{t \in(0,1]}\right)=\sigma^{2}+\underbrace{\pi^{2}(n-1)\left(\frac{\pi+\lambda \sigma^{2}}{2 \pi+\lambda \sigma^{2}}\right)^{2} \eta^{2}}_{\text {added variance }} ; \\
& \operatorname{Var}\left(p_{t \in(1,2]}\right)=\sigma^{2}+\overbrace{\pi^{2}(n-1)\left(\frac{\pi}{2 \pi+\lambda \sigma^{2}}\right)^{2} \eta^{2}} .
\end{aligned}
$$

2.2. Large Market-Induced Bankruptcy. While the bankruptcy of a large financial firm could come from mismanagement or fraud, we consider bankruptcies known or suspected to arise from market risk. Bankruptcies suspected of arising from market risk are also considered because strategic 
issues in exiting a large position cast doubt on legitimate claims of mismanagement. (Living counterparties may suspect market risk is to blame despite legitimate claims of mismanagement.)

2.2.1. Initial Bankruptcy. To study the effect of a market-induced bankruptcy, we impose an exogenous market return shock in period $0, r_{0}$, such that bankruptcy occurs for the most exposed counterparty (labeled counterparty $n$ for convenience). Mathematically, this means: $K+Q_{n} r_{0} \leq 0$ where $Q_{n} r_{0}<Q_{i} r_{0}$ for all $i<n$. For ease of exposition, we assume $Q_{n}$ is positive and $r_{0}$ is negative.

While the results are the same, we can consider two perpectives on $Q_{n}$. If living counterparties do not know $Q_{n}$, they can infer it from the market return preceding counterparty $n$ 's bankruptcy. ${ }^{6}$ With initial capital of $K$, the living counterparties estimate $Q_{n}$ as $\hat{Q}_{n}=E\left(Q_{n} \mid K+Q_{n} r_{0} \leq 0\right)$. Evaluating this expectation requires weak distributional assumptions and extreme value theory. (Appendix A.1 gives the derivation of $\hat{Q}_{n}$.) Alternately, we can endow all living counterparties with perfect information. In that case, they do know $Q_{n}$. We then view the use of $\hat{Q}_{n}$ as merely studying the most likely scenario for a given bankruptcy-inducing market return $r_{0}$.

For iid normal $Q_{i}$ 's, we estimate the maximum-likelihood initial large bankruptcy exposure as:

$$
\begin{aligned}
\hat{Q}_{n} & =E\left(Q_{n} \mid K+Q_{n} r_{0} \leq 0\right) \\
& =\frac{-K}{r_{0}}+\frac{\eta \sqrt{n-1}}{c_{n}\left(1-e^{-e^{-c_{n} \kappa_{1}-d_{n}}}\right)} \sum_{k=1}^{\infty} \frac{(-1)^{k+1} e^{-k\left(c_{n} \kappa_{1}+d_{n}\right)}}{k k !}
\end{aligned}
$$

where $c_{n}=\frac{1}{\sqrt{2 \log (n)}}, d_{n}=\sqrt{2 \log (n)}-\frac{\log \log (n)+\log \left(16 \tan ^{-1}(1)\right)}{2 \sqrt{2 \log (n)}}$, and $\kappa_{1}$ is the standardized maximum possible exposure of a living counterparty. If $Q_{n}$ is not known, $\kappa_{1}=\frac{-K}{r_{0} \eta \sqrt{n-1}}$.

$\overline{6_{\text {Till }} \text { (2006) infers }} Q_{n}$, albeit using different methods. 
2.2.2. Follow-On Bankruptcies. Since the broken contract is large, trading in periods 1 and 2 might cause follow-on bankruptcies. All broken contracts must be (in expectation) rehedged, and counterparties' mark-to-market payments depend on price impact and their positions subject to that impact.

Follow-on bankruptcies come from counterparties with exposures less than $\kappa_{1}=\frac{-K}{r_{0} \eta \sqrt{n-1}}$ and greater than $\kappa_{2}\left(\hat{Q}_{f}\right)$ which depends on the market structure. (Details are in Appendix A.2.)

We can then solve for the equilibrium distress pervasiveness $\hat{b}$ (the number of follow-on bankruptcies) and the distress exposure $\hat{Q}_{f}$ (the exposure annulled by follow-on bankruptcies):

$$
\begin{aligned}
\hat{b} & =E\left(b \mid K+Q_{n} r_{0} \leq 0\right) \\
& =(n-1)\left(1-\frac{\Phi\left(\kappa_{2}\right)}{\Phi\left(\kappa_{2}\right)}\right) \\
\hat{Q}_{f} & =E\left(Q_{f} \mid K+Q_{n} r_{0} \leq 0\right) \\
& =\frac{(n-1)^{3 / 2} \eta}{\Phi\left(\kappa_{1}\right)}\left(\phi\left(\kappa_{2}\left(\hat{Q}_{f}\right)\right)-\phi\left(\kappa_{1}\right)\right)
\end{aligned}
$$

where $\Phi$ and $\phi$ are the standard normal cdf and pdf.

A natural question is how sensitive follow-on bankruptcies are to an initial bankruptcy. One measure of the market's fragility or susceptibility to distress is the sensitivity of distress exposure, $\frac{\partial \hat{Q}_{f}}{\partial \hat{Q}_{n}}$; another measure is the sensitivity of distress pervasiveness, $\frac{\partial \hat{b}}{\partial \hat{Q}_{n}}$.

A valid criticism of these sensitivities is that counterparties going bankrupt with very little exposure would require a very large drop in the price of the risky asset - an unlikely event. To account for this, we can look at sensitivities weighted by the likelihood of such a precipitating $r_{0}$. Thus we would examine the likelihood-weighted sensitivity of distress exposure to see what size of initial bankruptcy is of greatest likely concern. 
2.2.3. Star Network. For a star network, only the CCP holds a broken contract. Thus only the CCP learns immediately of default. While such a default would become public knowledge quickly, the CCP also sees predatory trading immediately and can punish it.

Since only the CCP must rehedge, we can ignore low prices due to rehedging volatility. The additional unwanted exposure incurred by all counterparties due to follow-on bankruptcies, $\hat{Q}_{f}$, then results from counterparties with exposures between $\kappa_{1}$ and $\kappa_{2}\left(\hat{Q}_{f}\right)$ where

$$
\kappa_{2}\left(\hat{Q}_{f}\right)=\frac{-K p_{0}}{\eta \sqrt{n-1}\left(p_{0} r_{0}-\pi\left(\hat{Q}_{n}+\hat{Q}_{f}\right)\right)} .
$$

Since there are no worries about low prices and the CCP trades a fraction of the total trade $\nu=\frac{\pi+\lambda \sigma^{2}}{2 \pi+\lambda \sigma^{2}} \in[0,1]$ in period 1 , we may ignore the period 1 versus 2 distinction.

2.2.4. Complete Network. In a complete network, each living counterparty immediately detects default. Thus each living counterparty must trade to rehedge. This not only pushes the market further; the variation in rehedging trades also increases the volatility of the risky asset. That volatility also creates price extremes that are likely to be greater than the trading range from the rehedging of a CCP. A comparison of possible price paths (Figure 2) shows the difference in range.

We should expect more follow-on bankruptcies in complete networks for three reasons. First, extreme prices beyond the CCP rehedging price range will result in more counterparties being (expectationally) unable to pay mark-to-market. Second, counterparties with a small exposure will be driven by unwanted variance and may hedge completely in period 1 . Third, the fraction of hedging in period $1 \nu$ enters $\kappa_{2}$ and thus the follow-on exposure equation (14) in a way that creates a Prisoner's Dilemma situation. 

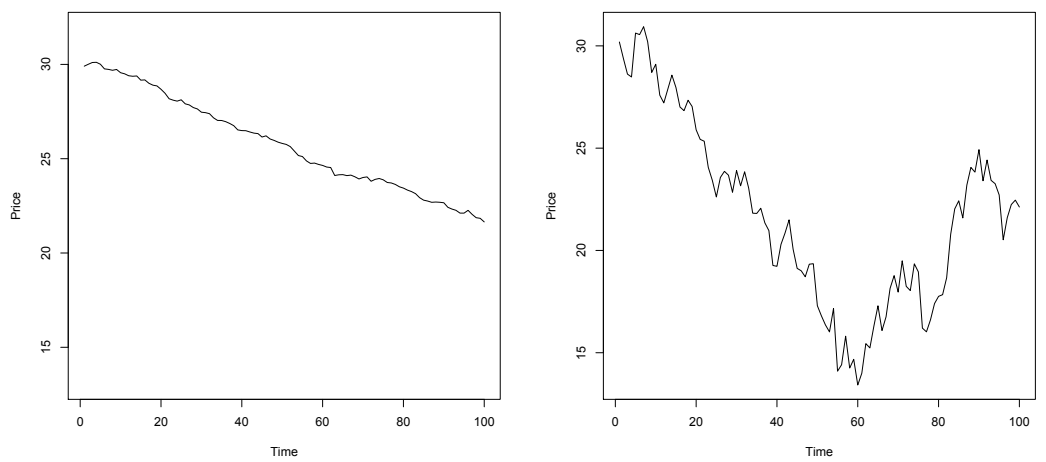

Figure 2. Possible price paths from $\$ 30$ to $\$ 24$ due to rehedging by a centralized counterparty (left) and bilateral OTC market participants (right).

If the overall fraction of the total rehedge traded in period 1 is $\nu$, the overall impact incurred for bilateral OTC markets will have three components. Two components, $\nu / 2$ and $(1-\nu) / 2$, are due to the random sequence of trading in periods 1 and 2 implying that each counterparty expects half of the other trades in that period to occur first. The third component, $(1-\nu) \nu$, is due to the position to be hedged in period 2 which incurs all impact of period 1 trading. The total impact is then $\frac{1}{2}+\nu-\nu^{2}$ which varies between $1 / 2(\nu=0$ or 1$)$ and $3 / 4(\nu=1 / 2)$. If we assume risk aversion $(\lambda>0)$, we would hope to be able to restrict our attention to the sub-interval $\nu \in\left[\frac{1}{2}, 1\right]$.

Trading by multiple counterparties with differing exposures creates high and low prices. Since we consider rehedgers who (net) sell, we estimate the low price and see how that effects follow-on bankruptcies. The low price is driven by the running sum of trades. That is approximated by a Brownian bridge, a Brownian motion tied to end at $-\left(\hat{Q}_{n}+\hat{Q}_{f}\right)$ and can be handled by time inversion. (See Appendix A.3 for details.) 
Thus the expected low quantity $\underline{S_{n-1}}$ of cumulated trades over trading periods 1 and 2:

$$
\begin{aligned}
& E\left(\underline{S_{n-1}} \mid S_{n-1}=-\left(\hat{Q}_{n}+\hat{Q}_{f}\right)\right)= \\
& \quad-\left(\hat{Q}_{n}+\hat{Q}_{f}\right)-\eta \sqrt{n-1} 2 \tan ^{-1}(1) \phi\left(\frac{\hat{Q}_{n}+\hat{Q}_{f}}{\eta \sqrt{n-1}}\right),
\end{aligned}
$$

and $\kappa_{2}\left(\hat{Q}_{f}\right)$ for this market structure:

$$
\kappa_{2}\left(\hat{Q}_{f}\right)=\frac{-K p_{0} /[\eta \sqrt{n-1}]}{p_{0} r_{0}-\pi E\left(\underline{S_{n-1} \mid} S_{n-1}=-\left(\hat{Q}_{n}+\hat{Q}_{f}\right)\right)} .
$$

This allows us to determine $\hat{Q}_{f}$ from (14).

If we were to solve the $n$-1-player game, we would have to solve an optimization of each player's mean-variance utility given the others' trades. This optimization then yields the period 1 fraction of trade $\nu$. Initial simulations suggest that heterogeneous rehedging needs - in particular the presence of long and short rehedgers - can yield values of $\nu$ in excess of 1 and even of the order $\nu=1.5-2$.

2.2.5. Destabilizing Phenomena. Such multi-player games reveal two phenomena of interest. While one phenomenon is unfortunate, the other is undesirable and may greatly destabilize the market. While these phenomena are always possible, they may easily affect or become the equilibrium solution in the large market-induced bankruptcy case.

The first of these phenomena is checkmate: when any action (or inaction) by a counterparty cannot be expected to avoid bankruptcy. Checkmate is unfortunate for the ensnared counterparty; they cannot hedge in such a way as to expect to stay in business by the end of period 2. Since the checkmated counterparty cannot expect to stay in business, it may be in their interest 
to do nothing in hopes of randomly avoiding period 2 bankruptcy. ${ }^{7}$ A necessary condition for checkmate is that closing the position would result in bankruptcy:

$$
-\pi Q_{n}^{2} / p_{0}+K<0 \Leftrightarrow Q_{n}>\sqrt{K p_{0} / \pi}
$$

Proposition 1 (Checkmate). In a complete network, there is a $Q_{n} \in(0, \infty)$ such that for some $k<n$ and any finite $x_{k}$ we expect bankruptcy in period 1: $E\left(\pi \sum_{j<n} x_{j} Q_{k} \mid \mathcal{F}_{1}\right)>K-Q_{k} r_{0}$.

What Proposition 1 means is that a large enough initial bankruptcy may result in an expected follow-on bankruptcy in period 1 despite the best efforts of the checkmated counterparty. This implies that policies restricting or taxing excess leverage might reduce distress (in this case, the number of market participants operating in checkmate). Note, however, that the leverage ratio implying checkmate varies with $1 / \sqrt{K}$.

The second phenomenon is hunting: when other counterparties expect to profit by inducing follow-on bankruptcies. This means some counterparties act to push prices further in a particular direction to make money. Normally, this is not possible in a market with price impact as we assume here. The invalidation of contracts with the bankrupted counterparty, however, makes profits possible.

Proposition 2 (Hunting). In a complete network of 3 or more counterparties, there is a $Q_{n} \in(0, \infty)$ such that for all exposures of $Q_{n}$ or greater, bankruptcy has a positive expected payoff for two or more other counterparties.

A sketch of the proof for $n=3$ offers insight into how hunting works.

\footnotetext{
${ }^{7}$ A checkmated counterparty might even seek to become "Too Big to Fail," in effect taking the market hostage to seek more favorable liquidation terms.
} 
Proof. Assume counterparty 3 is checkmated. Let $Q_{1}, Q_{2}<0<Q_{3}$ be such that $Q_{1}+Q_{2}=-Q_{3}$. Without loss of generality, we assume $q_{13}=Q_{1}$, i.e. counterparties 1 and 2 have no exposure to one another. For $\pi>0$, counterparties 1 and 2 trade $Q_{1}$ and $Q_{2}$ to replicate their counterparty 3 exposure, causing losses to counterparty 3: $\pi\left(Q_{1}+Q_{2}\right) Q_{3} / p_{0}+K<0$. Note that the market impact of trading by counterparties 1 and 2 is expected to bankrupt counterparty 3 .

The positive expected profit from such a strategy is due to the random ordering of trading. The first "hunter" to trade receives a mark-to-market profit due to the second hunter's trading. The expected profit is $E\left(P L_{i}\right)=$ $\pi \frac{Q_{1}+Q_{2}}{2 p_{0}} Q_{i}$. If counterparty 3 goes bankrupt, all contracts with counterparty 3 are canceled. The exposure of the hunting counterparties reverts from $2 Q_{i}$ back to $Q_{i}$.

If counterparty 3 does not go bankrupt, the hunting may continue or hunters may unwind their trades at no cost (since the market impact model is arbitrage-free).

2.2.6. A Separating Equilibrium? We can also examine a complete network from another perspective. Since we have multiple players, we can expect that there are multiple equilibria for how people would trade. One possible equilibrium is for rehedgers to separate themselves with buyers and sellers trading in different periods. We can see this by considering a large market drop which induces those who are long to sell.

Since the sellers are at risk of going bankrupt, they will sell in period 1 hoping to trade at the beginning of the period and not going bankrupt. This generates the typical "race for the exits." However, with only sellers in period 1, those whose sales are executed at the end of the period are likely to go bankrupt. Meanwhile, buyers wait to trade in period 2 at the lowest 
prices after sellers have bankrupted one another and pushed the market down.

In the extreme case, the buyers in period 2 would not even need to trade: bankruptcies in period 1 would annul their contracts and leave them flat. This possibility alone might support such an equilibrium.

With these sorts of dynamics, the period 2 trade is difficult to calculate. However, the result is the maximum distress in terms of volatility, low price, and follow-on bankruptcies. Thankfully, we can find the low price with only the net period 1 trade (which is easier to calculate).

We can think of the trades from buyers and sellers $x_{i}$ as adding up to some total trade quantity $\bar{Q}<0$. The question then is, what is the sum of all the sell trades? Mathematically, we want to know:

$$
E\left(\sum_{i=1}^{n-1}\left[x_{i}\right]^{-} \mid \sum_{i=1}^{n-1} x_{i}=\bar{Q}<0\right) .
$$

Unfortunately, this is a difficult question to answer. We approximate the answer by finding the expected sum of the absolute value of $n-1$ standard normal variables for a distribution with mean $\mu=-\bar{Q} /\left((n-1)^{3 / 2} \eta\right)$.

This is just (see Appendix A.5):

$$
\begin{aligned}
& E\left(\sum_{i=1}^{n-1}\left[x_{i}\right]^{-} \mid E \sum_{i=1}^{n-1} x_{i}=\bar{Q}<0\right) .= \\
& \quad=(n-1)^{3 / 2} \eta \phi(-\mu)+\bar{Q}(1-\Phi(-\mu)) .
\end{aligned}
$$

Note that the expected total sell trades scale with the $3 / 2$ power of the number of living counterparties (i.e. super-linearly). This suggests that such separating equilibria become destructive faster than a market's growth rate and that there might be a point where bilateral OTC markets transition from being robust to distress to being fragile. 


\section{EXAMPLES}

To get an idea of what different bankruptcies look like, we consider a market with $n=10$ counterparties, each having capital $K$ of $\$ 1$ million. Note that for a large bankruptcy these are very conservative assumptions: a market with counterparties having large exposures is likely to have more than 10 well-connected counterparties and, we generally expect trades to incur temporary impact — which would exacerbate the price extremes.

The risky asset has a price of $\$ 50$, daily price volatility of $\$ 0.95$ (equivalent to a $30 \%$ annual return volatility), and trades 5 million units daily. For the risky asset's price impact, we have that $\pi=2 \times 10^{-6}$. Risk aversion is a

daily $\lambda=1 \times 10^{-6}$. These parameter values are in line with examples in Almgren and Chriss (2001).

3.1. Small Bankruptcy Example. To see the effect of a small bankruptcy, we consider a market where counterparties hold contracts with exposure standard deviations of $\$ 100,000$.

In this case, the period 1 price impact is $-\$ 0.20$ and the period 2 price impact is $-\$ 0.17$. The price volatility increases to $\$ 1.30$ in period 1 and $\$ 1.11$ in period 2 . These are equivalent to return volatility increasing from $30 \%$ annualized to $41 \%$ and $35 \%$ annualized.

3.2. Large Bankruptcy Example. To get an idea of what a large financial bankruptcy looks like, we consider an example for $n=10$ counterparties, each having capital $K$ of $\$ 1$ million. The counterparties hold contracts equivalent to OTC contracts with a standard deviation $\eta$ of (also) $\$ 1$ million. We assume the CCP trades $\nu=0.5$ of the expected rehedge in period 1 ; however, for the CCP market structure, the results are not sensitive to $\nu$.

The risky asset has a price of $\$ 50$ and daily price volatility of $\$ 0.95$ (equivalent to a $30 \%$ annual volatility). For the risky asset's cash market liquidity, 
we have that $\pi=2 \times 10^{-6}$ and $\lambda=1 \times 10^{-6}$. These parameter values are in line with examples in Almgren and Chriss (2001).

This gives us the plot of follow-on bankruptcy exposure $\hat{Q}_{f}$ due to initial bankruptcy size $\hat{Q}_{n}$ shown in Figure 3 .
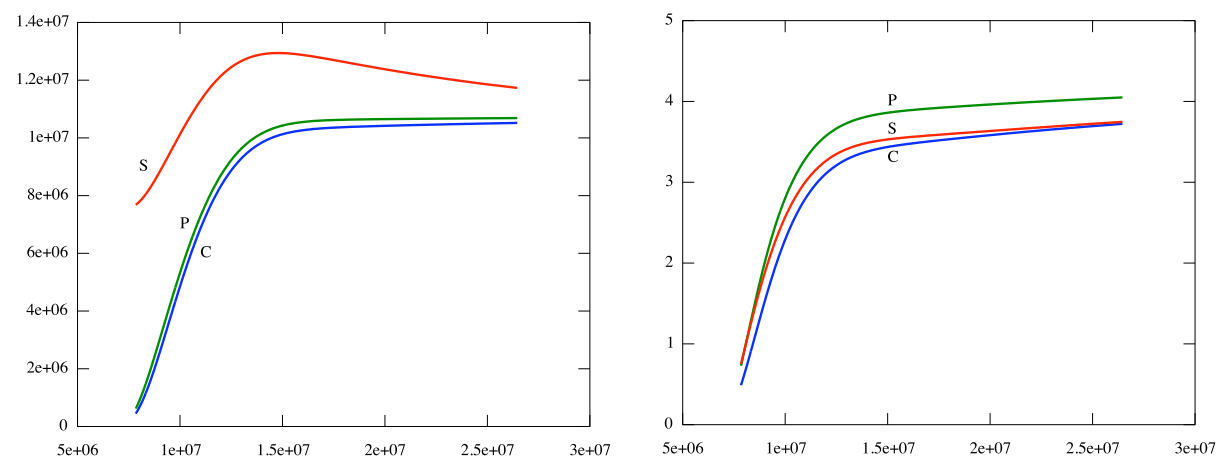

FiguRE 3. Follow-on bankruptcy exposure $\hat{Q}_{f}$ (left) and count $\hat{b}$ (right) versus initial bankruptcy size $\hat{Q}_{n}$ for $n=10$ counterparties, each with capital $K=\$ 1$ million, holding equivalent contracts with $\operatorname{sd}($ exposure $)=\$ 1$ million. Line $S$ is for a bilateral OTC market separating equilibrium where sellers and buyers trade in different periods. Line $P$ is for a bilateral OTC market with pooled buying and selling and overtrading by an amount typical from simulations $(1.75 \times)$. Line $C$ is for a market with central clearing.

We first consider the convex hull enclosing the central clearing market line $C$ and the bilateral OTC market lines $P$ and $S$. If buyers and sellers in the bilateral OTC market traded together and split their trades over periods 1 and 2 without trying to profit from one another (as for line $P$ ), their behavior would yield a line identical to $C$. However, simulations yielded an equilibrium where individuals behaved in a way that would yield line $P$. Thus we can think of the convex hull generated by lines $C, P$, and $S$ as the envelope of distress defining the space of possible distress equilibria. 
Since $P$ results from one equilibrium and $S$ results from another, we cannot ignore the difference between bilaterally-cleared (OTC) and centrallycleared markets. Further, that $C$ lies at the bottom of the envelope makes clear that distress is more likely and more destructive in markets without a central counterparty.

We can also note that the expected notional of contracts anulled by followon bankruptcies, $\hat{Q}_{f}$, is not monotonically increasing for the separating equilibrium $S$. This is because the total amount to be rehedged (i.e. including $Q_{n}$ ) is monotonically increasing; but, for larger bankruptcies, the initial failure dominates the total annulled exposure. It also suggests that for mid-sized bankruptcies, the uncertainty about the effect may increase the expected amount to rehedge; however, for very large bankruptcies the uncertainty about the net rehedge decreases.

While the separating equilibrium $S$ yields much greater follow-on bankruptcy exposure, it may well yield fewer expected follow-on bankruptcies than for pooled trading $P$. This suggests a "boiled frog" scenario: traders who panic may lose more in total; but, they may slightly increase their probability of survival. Traders who panic less (trading in periods 1 and 2; line $S$ ) incur mark-to-market losses from period 1 trading and incur half the losses (expectationally) in period 2. In other words, more traders may find themselves checkmated in period 2. This seeming paradox also lends support to the possibility of an equilibrium like that of line $S$.

From a policy perspective, we should consider the sensitivity of follow-on bankruptcy exposure $\hat{Q}_{f}$ to the initial bankruptcy $\hat{Q}_{n}$ : i.e. $\partial \hat{Q}_{f} / \partial \hat{Q}_{n}$. Figure 4 shows that both OTC market lines (pooled buyers and sellers, line $P$; separated buyers and sellers, line $S)$ and the central counterparty line $(C)$ have intervals where they are greater than 1 . In these intervals, a counterparty who could affect the initial bankruptcy size would generate rehedging 
(due to follow-on bankruptcies) in excess of their effect on $\hat{Q}_{n}$. This suggests that hunting is more than just an abstract or theoretical concept.
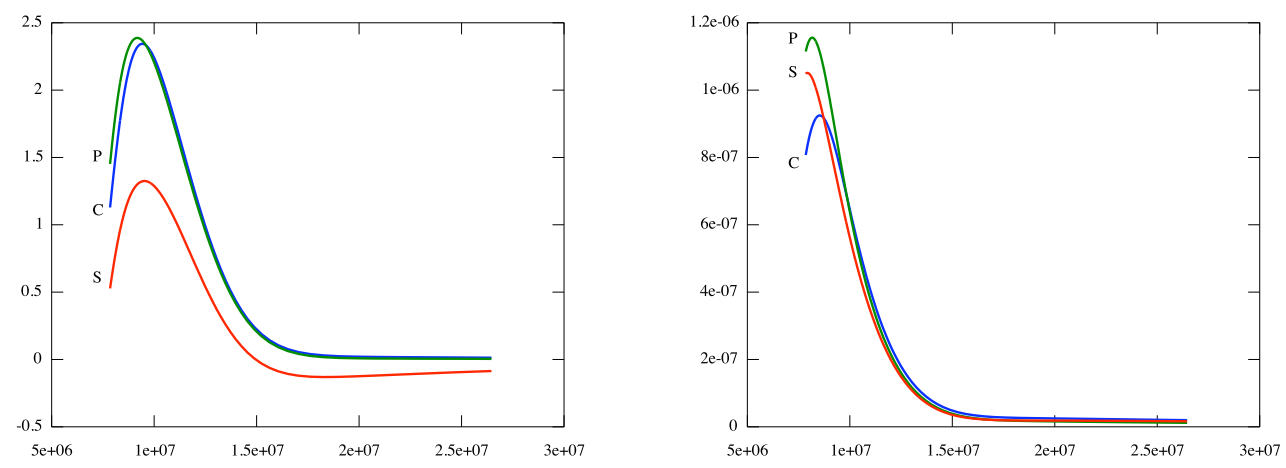

Figure 4. Sensitivity of distress exposure $\hat{Q}_{f}$ (left) and distress pervasiveness $\hat{b}$ (right) to an initial bankruptcy of size $\hat{Q}_{n}$, i.e. $\partial / \partial \hat{Q}_{n}$. Plot is for $n=10$ counterparties each with capital $K=\$ 1$ million and positions equivalent to OTC contracts with $\operatorname{sd}($ exposure $)=\$ 1$ million. Lines $C, P$, and $S$ correspond to a market with a central counterparty, pooled OTC buyers and sellers, and separated buyers and sellers.

This plot suggests that distress (follow-on bankruptcies) are most likely to be destructive for initial bankruptcies by counterparties having exposure of $\$ 11-\$ 14$ million to one risky asset with a capital base of $\$ 1$ million. While few firms hold one asset, anecdotal accounts and conditional correlations from Pesaran and Pesaran (2010) suggest some banks in the credit crisis saw the correlation of their assets reach levels of 0.7 or more. A correlation of 0.7 implies we can explain $R^{2}=0.7^{2}=0.49(49 \%)$ of the variance. Thus one risky asset having $\$ 11-\$ 14$ million of exposure could be thought of as similarly destructive to assets of $\$ 22-\$ 28$ million which become correlated at a level of 0.7 . This suggests leverage ratios of $22-28$ may be modal levels at which financial distress occurs. That is especially troubling since most investment banks have leverage ratios at least this great. 
This suggests that policies which restrict or tax leverage ratios beyond 22 (or so) may reduce distress and volatility externalities - even in markets with a central counterparty. Another possibility might be to auction permits to exceed some base leverage ratio and then allow financial companies to trade these permits (as is done with emissions permits). Aggressive investments banks with leverage ratios of 30-35 would thus be penalized relative to banks which earn similar profits on lower leverage.

3.3. Why Complete Networks May Be Fragile. The preceding findings contradict prior work on contagion in financial networks, in particular Allen and Gale (2000) and Nier, Yang, Yorulmazer, and Alentorn (2007). Those studies note that sparse networks are more fragile and exhibit greater contagion than complete networks (which they characterize as robust). The work here differs because the prior studies do not allow for the possibility of buyer-seller separation.

In Allen and Gale (2000) and Nier, Yang, Yorulmazer, and Alentorn (2007), a sparse (ring) network is compared to a complete network. ${ }^{8}$ However, both studies assume complete networks allow for the cost of contagion to be spread among the other players. This implicitly assumes that all contracts will incur similar losses of exposure when a given counterparty goes bankrupt. (Nier, Yang, Yorulmazer, and Alentorn (2007) make this explicit by dividing a node's net exposure among all other counterparties.)

In the complete network analyzed here, broken exposures are not necessarily all of the same sign. This means that some counterparties must buy to rehedge while others need to sell. It is this division of rehedgers into buyers

${ }^{8}$ Both Allen and Gale (2000) and Nier, Yang, Yorulmazer, and Alentorn (2007) study the interbank market for which a ring may mimic the lending agreements of banks in different regions. For financial markets, however, a ring is a highly unlikely market structure. Neither of these studies considers a central counterparty. 
and sellers that allows them to separate their rehedging intertemporally and increases the severity of the crisis.

3.4. Real Effects of the Large Bankruptcy Example. We should also consider some implications for the real effects of an example like this large bankruptcy. In particular, we consider the effects of an initial bankruptcy for exposure $\hat{Q}_{n}$ of $\$ 10$ million.

The effect on the risky asset price is stark. The market with a central counterparty would see the risky asset drop in price from $\$ 50$ to roughly $\$ 20$ (drop $=\pi \cdot \$ 15$ million $=\$ 30)$. In the bilateral OTC market with pooled buyers and sellers, the risky asset would drop in price from $\$ 50$ to $\$ 29(\pi \cdot \$ 15.5$ million $=\$ 31)$. However, if buyers and sellers in the bilateral market separate, the risky asset price will drop from $\$ 50$ to $\$ 10(\pi \cdot \$ 20$ million $=\$ 40)$. Thus the risky asset drops in price $33 \%$ more than in a market with a central counterparty.

The increase in volatility would persist for some time as suggested by most GARCH models. The CCP market would see volatility increase due to the period 1 return of $-60 \%$. The bilateral market with pooled buyers and sellers would see intraday volatility increase from $30 \%$ (annualized) to $328 \%$ plus an effect from the period 1 (daily) return of $-62 \%$. The bilateral market with self-separated buyers and sellers would see intraday volatility increase from $30 \%$ (annualized) to $596 \%$ plus an effect from the period 1 (daily) return of $-80 \%$. Using an average persistence of 0.98 for variances from Lamoureux and Lastrapes (1990), we can get the excess volatilities 
implied by the sum of (decaying) daily distress-elevated variances as

$$
\begin{gathered}
\tilde{\sigma}_{C C P}=\sqrt{\sum_{t=1}^{\infty} 0.98^{t} \frac{0.6^{2}-0.3^{2}}{250}}=0.23=23 \% \\
\tilde{\sigma}_{b i, p}=\sqrt{\sum_{t=1}^{\infty} 0.98^{t} \frac{3.28^{2}-0.3^{2}}{250}}=1.43=143 \% \\
\tilde{\sigma}_{b i, s}=\sqrt{\sum_{t=1}^{\infty} 0.98^{t} \frac{5.96^{2}-0.3^{2}}{250}}=2.66=266 \% .
\end{gathered}
$$

For an average risk aversion of $\bar{\lambda}=3$ and a market size of $2\left(\hat{Q}_{n}+\right.$ $\left.\hat{Q}_{f} \mid \hat{Q}_{n}, s\right)=2(\$ 10+\$ 10)$ million $=\$ 40$ million, this implies an externality distress cost of $\bar{\lambda} \frac{\tilde{\sigma}_{C C P}^{2}}{2} \times \$ 40$ million $=\$ 3.2$ million for the CCP market. Compare this to the externality cost of distress for the bilateral OTC market with pooled buyers and sellers of $\$ 123$ million. Worst is the externality cost of distress for the bilateral market with segregated buyers and sellers: $\$ 425$ million. Thus we can estimate that, for this market, the marginal externality cost of distress due to market structure is at least $\$ 120$ million and perhaps as much as $\$ 425-\$ 3=\$ 422$ million (3 to 11 times the size of the market). Obviously, these results would be even more disturbing if scaled up to sizes of markets which experienced recent distress. For a CDS market with $\$ 2.6$ trillion of net exposure (as per Phillips (2010)), this would imply an externality cost of distress of up to $\$ 28.6$ trillion. It is worth noting that current figures for the cost of the financial crisis are of the same order of magnitude.

These figures are only part of the story, however. If the externality cost of volatility exceeds the benfit of trading in a market, we can expect that market to cease trading. Although the model used here presumes all players continue to trade, we can use the model-implied volatility effects to reveal 
when markets fail. Obviously, the distress from such failure would exceed that predicted by the model.

A drop in allocative efficiency is another effect of systemic crisis. In the pre-crisis state, the average investor $(\bar{\lambda}=3)$ assuming an $8 \%$ equity premium and the previously-mentioned $30 \%$ volatility would hold a portfolio with $\frac{8 \%}{\lambda \sigma^{2}}=30 \%$ in the risky asset. Post-crisis, an investor in the CCP market would hold $\frac{8 \%}{\lambda\left(\tilde{\sigma}_{C C P}^{2}+\sigma^{2}\right)}=18.5 \%$ in the risky asset; an investor in the bilateral OTC market with pooled buyers and sellers would hold $1.2 \%$ in the risky asset; and, an investor in the bilateral OTC market with segregated buyers and sellers would hold only $0.4 \%$ of their portfolio the risky asset. If we believe holding $30 \%$ in the risky asset is allocatively efficient, then crises have a real inefficiency cost by suggesting to investors that they pay transactions costs to diverge (perhaps temporarily) from their pre-crisis holdings. Even if we say that market structure risk matters and view all of these holdings as allocatively efficient, we should still be surprised by different market structures suggesting holding anywhere from $18.5 \%$ to $0.4 \%$ of the risky asset post-crisis. This would also seem to suggest that bilateral OTC markets take longer to recover from crises since investors are more dissuaded from holding risky assets after a bilateral market crisis.

While few markets consists of only ten firms, many are dominated by about ten large intermediaries. In this case, a systemic crisis created by the bankruptcy of one intermediary would be serious. Further, the sensitivity of distress pervasiveness (Figure 4) suggests we could easily expect 2-3 followon bankruptcies of such large intermediaries after a decline of $\$ 1 \mathrm{MM} / \$ 15$ $\mathrm{MM}=$ roughly $7 \%$ in the value of all leveraged positions. Again, while we cannot easily equate this model with the recent financial crisis, we can note that after Lehman Brothers' bankruptcy that Bank of America, Citigroup, 
and Goldman Sachs were thought to be near bankruptcy. Thus this model does not disagree with recently observed effects.

Recent averages from Harper (2010) suggest such intermediaries (large investment banks) each pay an average of $\$ 16.4$ billion in compensation per year and employ 134,000 people. Three bankruptcies (a major systemic crisis) would unemploy about 400,000 employees and, assuming one year of unemployment and $40 \%$ overall taxes, a loss of $\$ 19.7$ billion in tax revenues. Further costs would include unemployment benefits.

Moreover, these firms are not useless: they exist to do more than just pay their employees. These firms provide services necessary for the smooth functioning of capital markets and the macroeconomy. While the effects of a crisis due to impairment of these firms may be more difficult to estimate, we know that the effects are serious. Bernanke (1983) notes that such crises may affect market making and information-gathering services provided by these firms. That in turn reduces the efficiency of the financial sector and may lead to expensive credit, economic contraction, and even depression.

\section{Conclusion}

We have shown that different network structures of exposures and markto-market payments can yield different market effects when an exogenous shock is introduced and trades have price impact. These effects are apart from any concerns about adverse selection and are due strictly to market structure.

The bankruptcy of a small non-financial firm increases the volatility of a risky asset held by the failed firm. Further, we can model this increased volatility as a function of exposures to the failed counterparty and market impact parameters. 
The bankruptcy of a large financial firm is shown to be more destructive: counterparties may be checkmated (unable to avoid expected bankruptcy), and counterparties may hunt the weak (seek to bankrupt counterparties) for positive expected profit. Thus counterparty risk becomes transmuted into systemic risk. In the extreme case, buyers and sellers may separate when they trade, causing greatly increased follow-on bankruptcies, market swings, and volatility. This reduces market liquidity and could therefore touch of a vicious cycle of reducing funding and market liquidities as suggested by Brunnermeier and Pedersen (2009). This also suggests that complete networks have more potential for contagion than star networks and other sparse networks - a result counter to Allen and Gale (2000) and Nier, Yang, Yorulmazer, and Alentorn (2007).

Both of these cases, small and large bankruptcies, have policy implications for market structures. In the large bankruptcy case, one example suggests that leverage ratios in the mid-20's may be modal for distress and may cause the most destruction relative to the size of the initial bankruptcy. This is especially troubling since many investment banks have leverage ratios in the 20 's to low 30's. Further, the number of bankruptcies implied by the model allows us to guess at the unemployment caused by distress and the resulting loss in tax revenues.

These models also show that distress and rehedging leads to increased volatility. This increased volatility is clearly an externality. Using an aggregate risk-aversion parameter, that externality may be priced to estimate the cost of differing market structures under stress. The increased volatility may lead investors to expend effort and cash to rebalance their portfolios and creates allocative inefficiencies. Further, extreme volatility may pose such high externality costs that markets cease to function. 
The results also suggest there is a benefit to trading on centrally-cleared (and perhaps even exchange-traded) markets versus bilaterally-cleared OTC markets. However, bilateral markets have small startup costs and are thus important for financial innovation. If we could price the evolution of that flexibility, we might know more about when to offer incentives for trading to migrate from bilaterally-cleared to centrally-cleared markets. Given that the recently-passed Dodd-Frank financial reform bill encourages such transitions, these findings may help policymakers determine when is the best time to move markets to central clearing.

While monitoring exposures and capital levels is critical, it is not enough. The models here show the value of monitoring the distribution of exposures, how many players are in a network, and how connected the network is. Obviously, this suggests a need for more financial transaction reporting. However, whether such reporting will result from Dodd-Frank (via central clearing of derivatives or formal reporting) is not yet clear.

We also see that the follow-on distress pervasiveness $\hat{b}$ and exposure $\hat{Q}_{f}$ are useful metrics for how destructive a crisis might be and that their sensitivities $\partial \hat{b} / \partial Q_{n}$ and $\partial \hat{Q}_{f} / \partial Q_{n}$ are useful metrics of market fragility. When $\partial \hat{Q}_{f} / \partial Q_{n}>1$, we should expect to see checkmate and hunting.

Hunting poses a Prisoner's Dilemma situation: counterparties hurt themselves by rehedging to avoid losses from other rehedgers. This suggests a reason for concerted action by market authorities in times of severe distress. One could view the Federal Reserve's forcing 15 banks to collectively takeover LTCM as such an action.

This model can be extended to further study counterparty and systemic risks. Various fixes could be explored to the unsatisfactory assumption that all trading occurs with an external counterparty outside the network. In particular, we should study the marginal effect of adding a market maker 
concerned about adverse selection or even counterparty risk when trading; and, we might consider analyzing other network structures and other network metrics (such as minimum spanning trees). We should explore the possibilities of counterparties trading collusively to trigger mark-to-market profits or counterparties' risk aversions changing when contagion occurs. We could also examine the efficiency of capital usage if the CCP were endowed with capital aside from having claims on members' assets. ${ }^{9}$

Finally, we should consider how traders would react to these differing network structures. Given the differences in systemic risk and, possibly, capital charges (if we were to mimic how CCPs require posting margin), would the networks of exposures be the same, similar, or very different? ${ }^{10}$ This would require us to model network formation and to allow counterparties to enter the network endogenously. The results here lack that endogeneity because it is not necessary to study how market structures affect distress. While network formation would rest on the results developed here, it is sufficiently important to be an area of further study.

\section{Appendix A. Large Market-Induced Bankruptcy Derivations}

A.1. Expected Exposure for First Bankruptcy. We assume the $Q_{i}$ are normally distributed and use the Gumbel extreme value distribution for the

\footnotetext{
${ }^{9}$ Recent work by Biais, Heider, and Hoerova (2011) suggests that a CCP is capital efficient; however, that work is ongoing.

${ }^{10}$ I thank both Tim Johnson and Florian Heider for noting this important question.
} 
maximum $\left(Q_{n}\right)$ distribution. Since the $Q_{i}$ 's are iid we have

$$
\begin{aligned}
E\left(Q_{n} \mid K+Q_{n} r_{0} \leq 0\right) & =\eta \sqrt{n-1} \frac{\int_{\kappa_{1}}^{\infty} x c_{n} e^{-c_{n} x-d_{n}} e^{-e^{-c_{n} x-d_{n}}} d x}{\int_{\kappa_{1}}^{\infty} c_{n} e^{-c_{n} x-d_{n}} e^{-e^{-c_{n} x-d_{n}}} d x} \\
& =\eta \sqrt{n-1} \frac{\int_{c_{n} \kappa_{1}+d_{n}}^{\infty} \frac{u-d_{n}}{c_{n}} e^{-u} e^{-e^{-u}} d u}{1-e^{-e^{-c_{n} \kappa_{1}-d_{n}}}} \\
& =\frac{\eta \sqrt{n-1}}{c_{n}}\left(\frac{\int_{c_{n} \kappa_{1}+d_{n}}^{\infty} u e^{-u} e^{-e^{-u}} d u}{\left.1-e^{-e^{-c_{n} \kappa_{1}-d_{n}}}-d_{n}\right) .} .\right.
\end{aligned}
$$

where $\kappa_{1}=\frac{-K}{r_{0} \eta \sqrt{n-1}}, c_{n}=\frac{1}{\sqrt{2 \log (n)}}$, and ${ }^{11} d_{n}=\sqrt{2 \log (n)}-\frac{\log \log (n)+\log \left(16 \tan ^{-1}(1)\right)}{2 \sqrt{2 \log (n)}}$.

The integral of $u$ over the partial domain of the Gumbel distribution cannot be found in closed form. Therefore, we note that

$$
\begin{aligned}
\int_{a}^{\infty} u e^{-u} e^{-e^{-u}} d u & =\gamma-\int_{-\infty}^{a} u e^{-u} e^{-e^{-u}} d u=\gamma+\int_{e^{-a}}^{\infty} \log (v) e^{-v} d v \\
& \left.=\gamma-\log (v) e^{-v}\right]_{e^{-a}}^{\infty}+\int_{e^{-a}}^{\infty} \frac{e^{-v}}{v} d v \\
& =\gamma-a e^{-e^{-a}}+E_{1}\left(e^{-a}\right) \\
& =\gamma-a e^{-e^{-a}}+\left(-\gamma-\log \left(e^{-a}\right)-\sum_{k=1}^{\infty} \frac{(-1)^{k} e^{-k a}}{k k !}\right) \\
& =a-a e^{-e^{-a}}-\sum_{k=1}^{\infty} \frac{(-1)^{k} e^{-k a}}{k k !}
\end{aligned}
$$

\footnotetext{
${ }^{11}$ The arctangent function is used to preserve $\pi$ for the permanent impact parameter. A single appearance of a transcendental number should not curtail a convenient consonance.
} 
This then gives us

$$
\begin{aligned}
& E\left(Q_{n} \mid K+Q_{n} r_{0} \leq 0\right)=\frac{\eta \sqrt{n-1}}{c_{n}}\left(\frac{\int_{c_{n} \kappa_{1}+d_{n}}^{\infty} u e^{-u} e^{-e^{-u}} d u}{1-e^{-e^{-c_{n} \kappa_{1}-d_{n}}}}-d_{n}\right) \\
& =\frac{\eta \sqrt{n-1}}{c_{n}}\left(\frac{\left.a-a e^{-e^{-a}}+\sum_{k=1}^{\infty} \frac{(-1)^{k+1} e^{-k a}}{k k !}\right]_{c_{n} \kappa_{1}+d_{n}}}{1-e^{-e^{-c_{n} \kappa_{1}-d_{n}}}-d_{n}}\right) \\
& =\eta \sqrt{n-1}\left(\kappa_{1}+\frac{\sum_{k=1}^{\infty} \frac{(-1)^{k+1} e^{-c_{n} \kappa_{1}-d_{n}}}{k k !}}{c_{n}\left(1-e^{-e^{-c_{n} \kappa_{1}-d_{n}}}\right)}\right) \\
& =\frac{-K}{r_{0}}+\frac{\eta \sqrt{n-1}}{c_{n}\left(1-e^{\left.-e^{-c_{n} \kappa_{1}-d_{n}}\right)}\right.} \sum_{k=1}^{\infty} \frac{(-1)^{k+1} e^{-k\left(c_{n} \kappa_{1}+d_{n}\right)}}{k k !} .
\end{aligned}
$$

A.2. Exposure to Follow-On Bankruptcies. The number of follow-on bankruptcies $b$ has expectation $\hat{b}=E\left(b \mid K+Q_{n} r_{0} \leq 0\right)$ of:

$$
\hat{b}=(n-1) \frac{\int_{\kappa_{2}}^{\kappa_{1}} \phi(z) d z}{\int_{-\infty}^{\kappa_{1}} \phi(z) d z}=(n-1)\left(1-\frac{\Phi\left(\kappa_{2}\right)}{\Phi\left(\kappa_{1}\right)}\right)
$$

where $\kappa_{2}=\frac{-K /[\eta \sqrt{n-1}]}{r_{0}-\pi\left(\hat{Q}_{n}+\hat{Q}_{f}\right)\left(\frac{1}{2}+\nu-\nu^{2}\right)}$, and $\phi, \Phi$ are the standard normal pdf and cdf. The bounds $\kappa_{1}$ and $\kappa_{2}$ are assumed to be of the same sign — which fails if the direction of aggregate trading is opposite that needed for aggregate rehedging. This situation is ignored since such trading would be suboptimal.

We also have that the expected exposure of a bankrupted counterparty is

$$
E\left(Q \mid K+Q_{n} r_{0} \leq 0\right)=\frac{\eta \sqrt{n-1} \int_{\kappa_{2}}^{\kappa_{1}} z \phi(z) d z}{\int_{\kappa_{2}}^{\kappa_{1}} \phi(z) d z} .
$$

The additional unwanted exposure, $\hat{Q}_{f}=E\left(Q_{f} \mid K+Q_{n} r_{0} \leq 0\right)$, due to follow-on bankruptcies then follows from integration by parts and Wald's 
Formula:

$$
\begin{aligned}
\hat{Q}_{f} & =E\left(Q \mid K+Q_{n} r_{0} \leq 0\right) E\left(b \mid K+Q_{n} r_{0} \leq 0\right) \\
& =\frac{\eta \sqrt{n-1} \int_{\kappa_{2}}^{\kappa_{1}} z \phi(z) d z}{\int_{\kappa_{2}}^{\kappa_{1}} \phi(z) d z}(n-1) \frac{\int_{\kappa_{2}}^{\kappa_{1}} \phi(z) d z}{\int_{-\infty}^{\kappa_{1}} \phi(z) d z} \\
& =\frac{(n-1)^{3 / 2} \eta}{\Phi\left(\kappa_{1}\right)} \int_{\kappa_{2}}^{\kappa_{1}} z \phi(z) d z=\frac{(n-1)^{3 / 2} \eta}{\Phi\left(\kappa_{1}\right)}\left(\phi\left(\kappa_{2}\right)-\phi\left(\kappa_{1}\right)\right) .
\end{aligned}
$$

A.3. Expectation of Minimum Price. To find the maximum amount sold, we note that each trade is normally-distributed in size. Also, the order of trading is random, i.e. uniformly distributed across the $(n-1)$ ! different permutations. Let $x_{i}^{\prime}$ be the $i$-th trade, or $x_{i}^{\prime}=x_{\rho(i)}$ if $\rho$ is a permutation operator. Then, we let $S_{n^{\prime}}=\sum_{i=1}^{n^{\prime}} x_{i}^{\prime}, \underline{S_{n}}=\min _{n^{\prime} \in\{1, \ldots, n\}} S_{n^{\prime}}$, and $\overline{S_{n}}=\max _{n^{\prime} \in\{1, \ldots, n\}} S_{n^{\prime}}$.

Since the beginning and ending positions are constrained, we model the sum of trades $S_{n}$ as a Brownian bridge and use time inversion to handle our ending position. Starting from Karatzas and Shreve (1991), equation (4.3.40), we get

$$
P\left(\overline{S_{n-1}} \geq m \mid S_{n-1}=\hat{Q}_{n}+\hat{Q}_{f}\right)=e^{-2 \frac{m\left(m-\left(\hat{Q}_{n}+\hat{Q}_{f}\right)\right)}{(n-1) \eta^{2}}} .
$$

Integrating this gives us the expected exceedance of the high beyond an ending trade of $\hat{Q}_{n}+\hat{Q}_{f}$. (This is the opposite of what we are doing; but, the development here eases comparison with Karatzas and Shreve's formula.) 
Thus we have that

$$
\begin{aligned}
E\left(\overline{S_{n-1}} \mid\right. & \left.S_{n-1}=\hat{Q}_{n}+\hat{Q}_{f}\right)-\left(\hat{Q}_{n}+\hat{Q}_{f}\right)= \\
& =\int_{\hat{Q}_{n}+\hat{Q}_{f}}^{\infty} e^{-2 \frac{m\left(m-\left(\hat{Q}_{n}+\hat{Q}_{f}\right)\right)}{(n-1) \eta^{2}}} d m \\
& =\int_{\hat{Q}_{n}+\hat{Q}_{f}}^{\infty} e^{-2 \frac{m^{2}-m\left(\hat{Q}_{n}+\hat{Q}_{f}\right)+\left(\hat{Q}_{n}+\hat{Q}_{f}\right)^{2} / 4-\left(\hat{Q}_{n}+\hat{Q}_{f}\right)^{2} / 4}{(n-1) \eta^{2}}} d m \\
& =\eta \sqrt{n-1} e^{-\frac{1}{2}\left(\frac{\hat{Q}_{n}+\hat{Q}_{f}}{\eta \sqrt{n-1}}\right)^{2}} \int_{\hat{Q}_{n}+\hat{Q}_{f}}^{\infty} e^{-2\left(\frac{m-\left(\hat{Q}_{n}+\hat{Q}_{f}\right)}{\eta \sqrt{n-1}}\right)^{2}} d m \\
& =\eta^{2}(n-1) e^{-\frac{1}{2}\left(\frac{\hat{Q}_{n}+\hat{Q}_{f}}{\eta \sqrt{n-1}}\right)^{2}} \int_{0}^{\infty} e^{-2 v^{2}} d v .
\end{aligned}
$$

This implies, via symmetry, that

$$
\begin{array}{r}
E\left(\underline{S_{n-1}} \mid S_{n-1}=-\left(\hat{Q}_{n}+\hat{Q}_{f}\right)\right)= \\
-\left(\hat{Q}_{n}+\hat{Q}_{f}\right)-(n-1) \eta^{2} 2 \tan ^{-1}(1) \phi\left(\frac{\hat{Q}_{n}+\hat{Q}_{f}}{\eta \sqrt{n-1}}\right) .
\end{array}
$$

A.4. Derivatives of the Expected Utility Function. We first note that

$$
\begin{aligned}
& \frac{\partial \kappa_{2}}{\partial x_{i}}=\frac{K \pi}{(n-1) \eta\left(r_{0}+\pi\left(x_{i}+\hat{y}_{i}\right)\right)^{2}}, \quad \text { and } \\
& \frac{\partial \kappa_{2}}{\partial \hat{y}_{i}}=\frac{K \pi}{(n-1) \eta\left(r_{0}+\pi\left(x_{i}+\hat{y}_{i}\right)\right)^{2}}
\end{aligned}
$$

We also note that

$$
\begin{aligned}
\frac{\partial \hat{b}}{\partial x_{i}} & =-(n-1) \frac{\phi\left(\kappa_{2}\right)}{\Phi\left(\kappa_{1}\right)} \frac{\partial \kappa_{2}}{\partial x_{i}}=\frac{-K \phi\left(\kappa_{2}\right)}{\eta \pi x_{i}^{2}}, \text { and } \\
\frac{\partial \hat{b}}{\partial \hat{y}_{i}} & =-(n-1) \frac{\phi\left(\kappa_{2}\right)}{\Phi\left(\kappa_{1}\right)} \frac{\partial \kappa_{2}}{\partial \hat{y}_{i}}=\frac{-K \phi\left(\kappa_{2}\right)}{\eta \pi \hat{y}_{i}^{2}} .
\end{aligned}
$$

For mathematical ease, we assumed $Q_{n}>0$ and $r_{0}<0$; rehedgers must sell to recreate canceled positions. Thus the sign of the $\hat{b}$ derivatives makes sense: more selling increases the expected number of follow-on bankruptcies. 
We can now find derivatives for $\hat{Q}_{f}$ :

$$
\begin{aligned}
\frac{\partial \hat{Q}_{f}}{\partial x_{i}} & =-\frac{(n-1)^{2} \eta}{\Phi\left(\kappa_{1}\right)} \kappa_{2} \phi\left(\kappa_{2}\right) \frac{\partial \kappa_{2}}{\partial x_{i}} \\
& =\frac{\pi K^{2} \phi\left(\kappa_{2}\right)}{\eta \Phi\left(\kappa_{1}\right)\left(r_{0}+\pi\left(x_{i}+\hat{y}_{i}\right)\right)^{3}}
\end{aligned}
$$

and

$$
\begin{aligned}
\frac{\partial \hat{Q}_{f}}{\partial \hat{y}_{i}} & =-\frac{(n-1)^{2} \eta}{\Phi\left(\kappa_{1}\right)} \kappa_{2} \phi\left(\kappa_{2}\right) \frac{\partial \kappa_{2}}{\partial \hat{y}_{i}} \\
& =\frac{K^{2} \phi\left(\kappa_{2}\right) \pi}{\eta \Phi\left(\kappa_{1}\right)\left(r_{0}+\pi\left(x_{i}+\hat{y}_{i}\right)\right)^{3}} .
\end{aligned}
$$

Since $r_{0}<0$, these derivatives are negative. Thus more selling will increase the total exposure cancelled by follow-on bankruptcies.

Finally, we can differentiate player $i$ 's expected utility function with respect to period 1 trade $x_{i}$ :

$$
\begin{aligned}
& \frac{\partial \hat{U}_{i}}{\partial x_{i}}=-\lambda \sigma^{2}\left(\frac{\hat{Q}_{f}}{n-\hat{b}-1}-q_{i n}+x_{i}\right)\left(\frac{\frac{\partial \hat{Q}_{f}}{\partial x_{i}}+\frac{\hat{Q}_{f}}{n-\hat{b}-1} \frac{\partial \hat{b}}{\partial x_{i}}}{n-\hat{b}-1}+1\right) \\
& -\pi\left(\frac{\hat{y}_{i}}{2}+2 x_{i}\right) \\
& -\frac{\pi}{2}\left(q_{i n}+\hat{y}_{i}-\hat{Q}_{n}-\hat{Q}_{f} \frac{n-\hat{b}}{n-\hat{b}-1}\right)\left(\frac{\frac{\partial \hat{Q}_{f}}{\partial x_{i}}+\frac{\hat{Q}_{f}}{n-\hat{b}-1} \frac{\partial \hat{b}}{\partial x_{i}}}{n-\hat{b}-1}+1\right) \\
& -\frac{\pi}{2}\left(-\frac{\partial \hat{Q}_{f}}{\partial x_{i}}-\frac{\frac{\partial \hat{Q}_{f}}{\partial x_{i}}-\frac{\hat{Q}_{f}}{n-\hat{b}-1} \frac{\partial \hat{b}}{\partial x_{i}}}{n-\hat{b}-1}\right)\left(\frac{\hat{Q}_{f}}{n-\hat{b}-1}-q_{i n}+x_{i}\right) .
\end{aligned}
$$


Then we differentiate the expected other players' utility with respect to the expected period 1 net trade of others, $\hat{y}_{i}$ :

$$
\begin{aligned}
\frac{\partial \hat{U}_{(i)}}{\partial \hat{y}_{i}} & =-\lambda \sigma^{2}\left(\hat{Q}_{n}+\hat{Q}_{f} \frac{n-\hat{b}-2}{n-\hat{b}-1}+q_{i n}+\hat{y}_{i}\right) \cdot \\
& \left(\frac{\partial \hat{Q}_{f}}{\partial \hat{y}_{i}} \frac{n-\hat{b}-2}{n-\hat{b}-1}-\frac{\hat{Q}_{f}}{(n-\hat{b}-1)^{2}} \frac{\partial \hat{b}}{\partial \hat{y}_{i}}+1\right)-\pi\left(\frac{x_{i}}{2}+2 \hat{y}_{i}\right) \\
& -\pi\left(-\frac{\partial \hat{Q}_{f}}{\partial \hat{y}_{i}} \frac{n-\hat{b}-\frac{3}{2}}{n-\hat{b}-1}+\frac{\hat{Q}_{f}}{2(n-\hat{b}-1)^{2}} \frac{\partial \hat{b}}{\partial \hat{y}_{i}}\right)\left(\hat{Q}_{n}+q_{i n}+\hat{Q}_{f} \frac{n-\hat{b}-2}{n-\hat{b}-1}+\hat{y}_{i}\right) \\
& -\pi\left(\frac{x_{i}-q_{i n}}{2}-\hat{Q}_{n}-\hat{Q}_{f} \frac{n-\hat{b}-\frac{3}{2}}{n-\hat{b}-1}\right)\left(\frac{\partial \hat{Q}_{f}}{\partial \hat{y}_{i}} \frac{n-\hat{b}-2}{n-\hat{b}-1}-\frac{\hat{Q}_{f}}{\left(n-\hat{b}_{-1}\right)^{2}} \frac{\partial \hat{b}}{\partial \hat{y}_{i}}+1\right) .
\end{aligned}
$$

A.5. Expectation of One-Sided Trade Quantities. We start with the idea of finding the expected sell trades after rehedging a large bankruptcy by a counterparty who was long the market. This can be thought of as

$$
E\left(\sum_{i=1}^{n-1}\left[x_{i}\right]^{-} \mid \sum_{i=1}^{n-1} x_{i}=\bar{Q}<0\right)
$$

where $x_{i}$ is the amount traded by counterparty $i$ in period 1 and $\bar{Q}$ is the amount which would be rehedged if buyer and seller both traded anticipating bankruptcies.

Instead of solving this, we solve a similar approximating problem:

$$
E\left(\sum_{i=1}^{n-1}\left[x_{i}\right]^{-} \mid E \sum_{i=1}^{n-1} x_{i}=\bar{Q}<0\right) .
$$


This is much easier if we let $\mu=-\frac{\bar{Q}}{(n-1)^{3 / 2} \eta}$ :

$$
\begin{aligned}
& E\left(\sum_{i=1}^{n-1}\left[x_{i}\right]^{-} \mid E \sum_{i=1}^{n-1} x_{i}=\bar{Q}<0\right) .= \\
& \quad=(n-1) \sqrt{n-1} \eta \int_{0}^{\infty} \frac{z}{\sqrt{2 \pi}} e^{-\frac{(z-\mu)^{2}}{2}} d z \\
& \quad=(n-1)^{3 / 2} \eta \int_{-\mu}^{\infty} \frac{w+\mu}{\sqrt{2 \pi}} e^{-w^{2} / 2} d w \\
& \quad=(n-1)^{3 / 2} \eta\left(\frac{1}{\sqrt{2 \pi}} e^{-\mu^{2} / 2}+\mu(1-\Phi(-\mu))\right) .
\end{aligned}
$$

\section{REFERENCES}

Acharya, Viral V., Robert F. Engle, Stephen Figlewski, Anthony W. Lynch, and Marti G. Subrahmanyam, 2009, Centralized clearing for credit derivatives, in Viral V. Acharya, and Matthew Richardson, ed.: Restoring Financial Stability (Wiley: New York, NY).

Allen, Franklin, and Douglas Gale, 2000, Financial contagion, Journal of Political Economy 108, 1-33.

— , 2004, Financial intermediaries and markets, Econometrica 72, $1023-1061$.

Almgren, Robert, and Neil Chriss, 2001, Optimal execution of portfolio transactions, Journal of Risk 3, 5-39.

Bernanke, Ben S., 1983, Nonmonetary effects of the financial crisis in the propagation of the great depression, American Economic Review 73, 257276 .

Biais, Bruno, Florian Heider, and Marie Hoerova, 2011, Risk-sharing or risk-taking? counterparty risk, incentives and margins, Working Paper 1571065 SSRN.

Boudt, Kris, Ellen C. S. Paulus, and Dale W. R. Rosenthal, 2011, Funding liquidity, market liquidity and ted spread: A two-regime model, Working 
Paper 1668635 SSRN.

Brunnermeier, Markus K., and Lasse Heje Pedersen, 2009, Market liquidity and funding liquidity, Review of Financial Studies 22, 2201-2238.

Cifuentes, Rodrigo, Gianluigi Ferrucci, and Hyun Song Shin, 2005, Liquidity risk and contagion, Journal of the European Economic Association 3, 556566.

Duffie, Darrell, and Haoxiang Zhu, forthcoming, Does a central clearing counterparty reduce counterparty risk?, Review of Asset Pricing Studies $? ?$

Gai, Prasanna, and Sujit Kapadia, 2010, Contagion in financial networks, Proceedings of the Royal Society A 466, 2401-2423.

Harper, Christine, 2010, Goldman's pay pool shrinks fastest as traders' fortunes dwindle, Bloomberg News.

Heider, Florian, Marie Hoerova, and Cornelia Holthausen, 2009, Liquidity hoarding and interbank market spreads: The role of counterparty risk, Discussion Paper 2009-11S European Banking Center.

Huberman, Greg, and Werner Stanzl, 2004, Price manipulation and quasiarbitrage, Econometrica 74, 1247-1276.

Karatzas, Ioannis, and Steven E. Shreve, 1991, Brownian Motion and Stochastic Calculus (Springer Verlag) second edn.

Lamoureux, Christopher G., and William D. Lastrapes, 1990, Persistence in variance, structural change, and the garch model, Journal of Business and Economic Statistics 8, 225-234.

Melamed, Leo, 2009, For Crying Out Loud (John Wiley and Sons: New York).

Nier, Erlend, Jing Yang, Tanju Yorulmazer, and Amadeo Alentorn, 2007, Network models and financial stability, Journal of Economic Dynamics and Control 31, 2033-2060. 
Pesaran, Bahram, and M. Hashem Pesaran, 2010, Conditional volatility and correlations of weekly returns and the var analysis of 2008 stock market crash, Working Paper in Economics 1025 Cambridge University.

Phillips, Matt, 2010, Cds market: Fun facts to drop in cocktail party conversation, Wall Street Journal.

Till, Hilary, 2006, Edhec comments on the amaranth case: Early lessons from the debacle, Working paper EDHEC Risk and Management Research Center. 